\title{
Os estudos de gênero na Revista Tempos e Espaços em Educação:
} uma revisão sistematizada

\section{SILVA, Ivanderson Pereira da (Maceió, Alagoas, Brasil) ${ }^{1 *}$ DIAS, Alfrancio Ferreira (Aracaju, Sergipe, Brasil) ${ }^{2 * *}$ \\ RIOS, Pedro Paulo Souza (Salvador, Bahia, Brasil) ${ }^{3^{\text {t+x }}}$}

1 Universidade Federal de Alagoas, Departamento de Educação, Curso de Graduação em Pedagogia 2Universidade Federal de Sergipe, Departamento de Educação, Curso de Graduação em Pedagogia ${ }^{3}$ Universidade do Estado da Bahia, Departamento de Educação, Curso de Graduação em Pedagogia ORCID ID: https://orcid.org/0000-0001-9565-8785

ORCID ID: https://orcid.org/0000-0002-5562-0085*

ORCID ID: https://orcid.org/0000-0001-7981-9091**

\begin{abstract}
Resumo
Realiza-se uma revisão sistematizada da literatura específica sobre gênero publicada na Revista Tempos e Espaços em Educação no período de 2014 a 2019. A ênfase se deu no processo metodológico que produziu os diferentes resultados encontrados nos estudos segundo a metodologia de revisão sistematizada. Verificou-se, a partir da seleção de variáveis e de critérios de inclusão/exclusão, que a literatura específica sobre gênero publicada no referido periódico sugere significativa ampliação na produção científica dos estudos de gênero, contribuindo para a desestabilização de normatizações, classificações e hierarquizações no campo da educação.
\end{abstract}

Palavras-chave

Gênero. Revisão sistematizada. Revista Tempos e Espaços em Educação.

\section{Gender studies in the Tempos e Espaços em Educação Journal:}

\section{a systematized review}

\begin{abstract}
In this article we carried out a systematic review of the specific literature on gender, published in Tempos e Espaços em Educação Journal between 2014 and 2019. The emphasis was on the methodological process that produced the different results found in the studies, based on the methodology of systematic review. Based on the selection of variables and inclusion/exclusion criteria, it was found that the specific gender literature published in Tempos e Espaços em Educação Journal suggests a significant expansion in the scientific production of gender studies, contributing to the destabilization of norms, classifications and hierarchies in the field of Education.
\end{abstract}

\section{Keywords}

Gender. Systematic review. Tempos e Espaços em Educação Journal. 


\title{
Estudios de género en la Revista Tempos e Espaços em Educação: una revisión sistemática
}

\begin{abstract}
Resumen
Se realizó una revisión sistemática de la literatura específica de género publicada en la Revista Tempos e Espaços em Educação de 2014 a 2019. El énfasis se situó en el proceso metodológico que produjo los diferentes resultados encontrados en los estudios de acuerdo con la metodología de revisión sistemática. Se encontró, con base en la selección de variables y criterios de inclusión / exclusión, que la literatura específica sobre género publicada en esa revista sugiere una expansión significativa en la producción científica de estudios de género, contribuyendo a la desestabilización de las normas, clasificaciones y jerarquías en el campo de la educación.
\end{abstract}

\section{Palabras clave}

Género. Revisión sistemática. Revista Tempos e Espaços em Educação.

\section{Introdução}

Observamos um crescimento significativo da produção científica sobre gênero e sexualidade na última década em diversas áreas do conhecimento, especificamente no campo da educação. Uma característica que é comum nesses estudos é o fato de sugerirem que a discussão séria sobre esses temas contribui para a desestabilização de normatizações, classificações e hierarquizações (DIAS; AMORIM, 2015; DIAS; OLIVEIRA, 2015; DIAS; OLIVEIRA; SANTOS, 2018; RIOS; CARDOSO; DIAS, 2018).

Perante o volume de estudos que discutem questões de gênero e que são publicados em revistas científicas que têm como foco a divulgação de relatos de pesquisa em Educação, evidencia-se a necessidade de socializar com a comunidade acadêmica da área sínteses que destaquem os avanços e as lacunas teóricas acerca do tema em tela. Dentre as alternativas metodológicas para esse fim, Dias e Amorim (2015) e Dias, Oliveira e Santos (2018) apontam a revisão sistematizada de literatura.

Para esta investigação, tomamos como base de dados a Revista Tempos e Espaços de Educação (REVTEE), em sua versão on-line ${ }^{1}$, periódico de publicação trimestral editado pelo Programa de Pós-Graduação em Educação da Universidade Federal de Sergipe. A REVTEE iniciou em formato impresso no ano de 2010 e a partir de 2014 passou para o formato on-line. Esse periódico se dedica à publicação de artigos

1 Disponível em: https://seer.ufs.br/index.php/revtee/index. Acesso em: 10 fev. 2020. ISSN: 2358-1425.

Educação \& Formação, Fortaleza, v. 5, n. 14, p. 150-175, maio/ago. 2020

DOI: https://doi.org/10.25053/redufor.v5i14mai/ago.2495

http://seer.uece.br/redufor 
acadêmico-científicos, fomentando e facilitando o intercâmbio acadêmico no âmbito nacional e internacional, o qual se dirige a professores, estudantes e pesquisadores das áreas das Ciências Humanas, com ênfase em estudos sobre Educação.

Ao explorar os números e volumes da REVTEE, observamos significativo número de artigos com foco em temas emergentes da relação entre gênero e Educação. Nesse sentido, emergiu o seguinte problema de pesquisa: que avanços e lacunas teóricas acerca das pesquisas com foco em questões de gênero a sistematização de estudos publicados na REVTEE pode revelar? Em face dessa questão, delineamos os seguintes objetivos: identificar a literatura específica sobre gênero na REVTEE; analisar as contribuições dos estudos encontrados para a relação entre gênero e Educação; apontar possíveis lacunas teóricas concernentes a esse tema. Para isso, organizamos este texto em duas partes: a primeira descreve o processo da revisão sistematizada; e a segunda aponta a discussão dos resultados encontrados.

\section{0 processo da revisão sistematizada}

A revisão sistematizada de literatura consiste numa abordagem de pesquisa que vem sendo explorada com mais frequência nos últimos dez anos, em função da necessidade de apontar o que já se produziu a respeito de um determinado tema, bem como "[...] verificar lacunas nesses dados para o direcionamento de novos estudos sobre o tema" (SANTOS; SILVA, 2018, p. 142).

Segundo Silva e Mercado (2019, p. 51), esse tipo de estudo "[...] comumente se baseia na análise de um levantamento que busca aprimorar a compreensão sobre a questão enfocada". Assim, inicialmente se reúne um conjunto de estudos já publicados sobre o tema em questão e na sequência se procede à sistematização. Ao longo da sistematização, não se "[...] deve apenas levantar informações, mas perceber como essas informações estão sendo usadas" (SANTOS; SILVA, 2018, p. 142).

No campo da Educação, de modo específico, a revisão sistematizada contribui para a "[...] a concentração de resultados de vários outros estudos num mesmo trabalho, aumentando a confiabilidade e revelando o status de um problema de pesquisa" (DIAS; AMORIM, 2015, p. 196). Ante o potencial dessa abordagem de pesquisa, neste estudo 
optamos por utilizar o planejamento desenvolvido por Cooper (2010), já explorado no campo da Ciência Política (FIGUEIREDO FILHO et al., 2014).

Esse planejamento de pesquisa está organizado em sete etapas: a) identificação e formulação do problema de pesquisa; b) coleção de literatura (neste caso, o levantamento dos artigos na REVTEE); c) coleta de informações de cada estudo; d) avaliação da qualidade dos estudos; e) análise e síntese dos resultados dos estudos; f) interpretação dos dados coletados; e g) apresentação dos resultados.

Para a coleção de literatura, ou seja, a delimitação do material a ser sistematizado, é necessário se definir procedimentos de exclusão/inclusão. Nesta pesquisa, utilizamos os seguintes critérios de exclusão/inclusão: a) o artigo deveria estar publicado na REVTEE no período de 2014 a 2019 (período que o periódico passou a ter sua versão on-line); b) o artigo poderia estar publicado em qualquer idioma; c) o termo "gênero" deveria estar presente no título, no resumo ou nas palavras-chave do artigo.

Definidos os critérios de inclusão/exclusão, realizamos a coleta de informações de cada estudo e avaliamos sua pertinência a partir da consulta aos títulos, resumos e palavras-chave. Uma vez realizada a etapa do levantamento, procedemos à análise, à síntese e à interpretação dos dados coletados, conforme planejamento proposto por Cooper (2010). A apresentação dos resultados e as discussões acerca do material levantado estão dispostas a seguir.

\section{Resultados e discussões}

Verificamos 21 edições e 409 artigos publicados no período de 2014 a 2019 na REVTEE. A partir dos critérios de inclusão/exclusão, selecionamos 40 artigos que tinham como foco questões que emergiam da relação entre gênero e Educação. Esse volume de artigos representa cerca de $10 \%$ do número total de estudos publicados pela REVTEE no período compreendido para este levantamento. O Quadro 1 apresenta os estudos que foram levantados. 


\section{Quadro 1 - Artigos incluídos}

\begin{tabular}{|c|c|c|c|c|}
\hline & & & & \\
\hline \begin{tabular}{l}
\multicolumn{1}{c}{ RODRIGUES, } \\
FARO, L. C. A.
\end{tabular} & $\begin{array}{l}\text { Entre fronteiras semoventes: a constituição do feminino } \\
\text { das filhas de lemanjá }\end{array}$ & 12 & 29 & 2019 \\
\hline $\begin{array}{l}\text { SILVA JUNIOR, P. M.; } \\
\text { IVENICKI, A. }\end{array}$ & $\begin{array}{l}\text { Entre sexualidades, masculinidades e raça: contribuições } \\
\text { do multi/interculturalismo para a prática pedagógica }\end{array}$ & 12 & 29 & 2019 \\
\hline GUZZI, J. & $\begin{array}{l}21 \text { gramos: el amor como epifenómeno de la tensión } \\
\text { cuerpo-alma }\end{array}$ & 12 & 29 & 2019 \\
\hline DONATO, A.; TONELLI, L. & A resistência do corpo & 12 & 28 & 2019 \\
\hline CARDOSO, H. M. & $\begin{array}{l}\begin{array}{l}\text { Gênero, sexualidade e escola: contribuições da } \\
\text { teorização de Foucault }\end{array} \\
\end{array}$ & 11 & 1 & 2019 \\
\hline $\begin{array}{l}\text { SANTOS, } \quad \text { A. } \\
\text { FELDENS, D. G. }\end{array}$ & $\begin{array}{l}\text { Vozes do triunfo: narrativas de si de professoras da } \\
\text { educação básica }\end{array}$ & 11 & 1 & 2019 \\
\hline $\begin{array}{l}\text { SILVA, M. M. M. T.; } \\
\text { TAVARES, C. }\end{array}$ & $\begin{array}{l}\text { Mulheres na luta: participação de mulheres nas } \\
\text { ocupações de } 2016 \text { na Universidade Federal de } \\
\text { Pernambuco }\end{array}$ & 11 & 27 & 2018 \\
\hline DUBET, F. & A escola "embaraçada" com a educação mista & 11 & 25 & 2018 \\
\hline $\begin{array}{l}\text { KAPLAN, C. V.; XAVIER, } \\
\text { N. R. }\end{array}$ & $\begin{array}{l}\text { As infâncias na literatura latino-americana: quais os } \\
\text { lugares da menina e da mulher negras? }\end{array}$ & 11 & 25 & 2018 \\
\hline $\begin{array}{l}\text { DIAS, A. F.; MENEZES, } \\
\text { C. A. A. }\end{array}$ & $\begin{array}{l}\text { Que inovação pedagógica a pedagogia queer propõe } \\
\text { ao currículo escolar? }\end{array}$ & 10 & 23 & 2017 \\
\hline $\begin{array}{l}\text { COUTO, A. S.; CRUZ, M. } \\
\text { H. S. }\end{array}$ & $\begin{array}{l}\text { Inserção de gênero no currículo de História e a } \\
\text { formação para o trabalho docente }\end{array}$ & 10 & 23 & 2017 \\
\hline ALMEIDA, W. R. A. & Uniforme escolar e uniformização dos corpos & 10 & 22 & 2017 \\
\hline $\begin{array}{l}\text { PINTO, É. J. S.; CARVALHO, } \\
\text { M. E. P.; RABAY, G. }\end{array}$ & As relações de gênero nas escolhas de cursos superiores & 10 & 22 & 2017 \\
\hline ARAÚJO, E.; BARROS, V. & $\begin{array}{l}\text { "Modo Deadline": uma análise sobre o tempo das } \\
\text { mulheres académicas }\end{array}$ & 10 & 22 & 2017 \\
\hline $\begin{array}{l}\text { SANTOS, É. S.; LAGE, A. } \\
\text { C. }\end{array}$ & $\begin{array}{l}\text { Gênero e diversidade sexual na educação básica: um } \\
\text { olhar sobre o componente curricular Direitos Humanos } \\
\text { e Cidadania da rede de ensino de Pernambuco }\end{array}$ & 10 & 22 & 2017 \\
\hline DIAS, A. F. et al. & Schooling and subversions of gender & 10 & 22 & 2017 \\
\hline GALAK, E. & $\begin{array}{l}\text { Pedagogías del cuerpo y del carácter en la "Revista de } \\
\text { Educación" durante la gobernación de José Luís } \\
\text { Cantilo (Buenos Aires, 1922-1926) }\end{array}$ & 10 & 21 & 2017 \\
\hline $\begin{array}{l}\text { CARVALHO, M. E. P. et } \\
\text { al. }\end{array}$ & $\begin{array}{l}\text { Origins and challenges of gender studies centers in } \\
\text { higher education in NorthERN and Northeastern Brazil }\end{array}$ & 10 & 21 & 2017 \\
\hline $\begin{array}{l}\text { FRANÇA, F. } \quad \text { G. } \\
\text { FERRARI, A. }\end{array}$ & $\begin{array}{l}\text { Mais do que professores/as, professores/as } \\
\text { homossexuais na escola }\end{array}$ & 9 & 20 & 2016 \\
\hline SANTANA, J. V. J. et al. & $\begin{array}{l}\text { Constituindo gêneros: sobre a produção de } \\
\text { masculinidades e feminilidades na educação infantil }\end{array}$ & 9 & 20 & 2016 \\
\hline $\begin{array}{l}\text { COSTA, P. R. S. M.; } \\
\text { MACARRO, M. J. M. }\end{array}$ & $\begin{array}{l}\text { Los aspectos educativos de la Ley Orgánica } 01 / 2004 \\
\text { de } 28 \text { de diciembre, de medidas de protección integral } \\
\text { contra la violencia de género }\end{array}$ & 9 & 20 & 2016 \\
\hline $\begin{array}{l}\text { PREINFALK-FERNÁNDEZ, } \\
\text { M. L. }\end{array}$ & $\begin{array}{l}\text { La educación sexual en el sistema educativo formal } \\
\text { costarricense }\end{array}$ & 9 & 19 & 2016 \\
\hline $\begin{array}{l}\text { PORTO, R.; GALVÃO, F. } \\
\text { D. }\end{array}$ & $\begin{array}{l}\text { De Slutwalk à Marcha das Vadias: o imperativo dos } \\
\text { feminismos em Natal (RN) }\end{array}$ & 9 & 19 & 2016 \\
\hline $\begin{array}{l}\text { BECKER, S.; OLIVEIRA, } \\
\text { E. A. }\end{array}$ & $\begin{array}{l}\text { Educação e direitos para (in)humanos? Desafios e } \\
\text { reflexões sobre os dilemas de LGBTs perante o } \\
\text { discurso jurídico brasileiro }\end{array}$ & 9 & 19 & 2016 \\
\hline RODRIGU & $\begin{array}{l}\text { Transgredir para empoderar: o empoderamento das } \\
\text { jovens mulheres pela educação }\end{array}$ & 9 & 18 & 2016 \\
\hline
\end{tabular}

Educação \& Formação, Fortaleza, v. 5, n. 14, p. 150-175, maio/ago. 2020

DOI: https://doi.org/10.25053/redufor.v5i14mai/ago.2495

http://seer.uece.br/redufor 


\section{Quadro 1 - Artigos incluídos}

\begin{tabular}{|c|c|c|c|c|}
\hline & & & & \\
\hline Autor & Título & V. & N. & Ano \\
\hline $\begin{array}{l}\text { MORAIS, A. B. A.; } \\
\text { CARVALHO, M. E. P. }\end{array}$ & $\begin{array}{l}\text { Institucionalização dos estudos de gênero na } \\
\text { universidade: uma análise a partir de narrativas de } \\
\text { acadêmicas feministas }\end{array}$ & 8 & 17 & 2015 \\
\hline $\begin{array}{l}\text { EUGÊNIO, B. G.; LIMA, A. } \\
\text { O. }\end{array}$ & $\begin{array}{l}\text { Imagens de negros e negras no livro didático de } \\
\text { História dos anos iniciais do ensino fundamental }\end{array}$ & 8 & 16 & 2015 \\
\hline $\begin{array}{l}\text { VIEIRA, C. M.; COELHO, } \\
\text { M. A. }\end{array}$ & $\begin{array}{l}\text { Sexualidade e deficiência intelectual: concepções, } \\
\text { vivências e o papel da educação }\end{array}$ & 7 & 14 & 2014 \\
\hline CRUZ, M. H & $\begin{array}{l}\text { A crítica feminista à ciência e contribuição à pesquisa } \\
\text { nas Ciências Humanas }\end{array}$ & 7 & 12 & 2014 \\
\hline $\begin{array}{l}\text { THÜRLER, D.; } \quad \text { DOS } \\
\text { SANTOS, J. L. }\end{array}$ & $\begin{array}{l}\text { Um debate sobre a escola como tecnologia político- } \\
\text {-cultural }\end{array}$ & 7 & 12 & 2014 \\
\hline SARAT, M.; CAMPOS, M. I. & Gênero, sexualidade e infância: (con)formando meninas & 7 & 12 & 2014 \\
\hline FERREIRA, M. M. & $\begin{array}{l}\text { Relações de classe e gênero na escola: revisitando } \\
\text { conceitos de igualdade, desigualdade, diferença, } \\
\text { classe e gênero }\end{array}$ & 7 & 12 & 2014 \\
\hline $\begin{array}{l}\text { ANJOS, J. P.; CARDOSO, } \\
\text { L. R. }\end{array}$ & Hanami ou corpos fogem, vazam, escapam... & 7 & 12 & 2014 \\
\hline $\begin{array}{l}\text { DI GREGORIO, M. F.; } \\
\text { SILVA, K. N. }\end{array}$ & $\begin{array}{l}\text { Gênero e sexualidade no lócus família/escola: } \\
\text { incursões deflagradas à não heterossexualidade e os } \\
\text { desafios para a cidadania reconhecida }\end{array}$ & 7 & 12 & 2014 \\
\hline $\begin{array}{lll}\text { CANOTILHO, } & \text { A. } & \text { P.; } \\
\text { ARAUJO, N. } & \text { F.; } & \text { DE } \\
\text { OLIVEIRA, S. M. T. } & \end{array}$ & $\begin{array}{l}\text { A contribuição da escola para a emancipação das } \\
\text { mulheres }\end{array}$ & 7 & 12 & 2014 \\
\hline DIAS, A. F. & $\begin{array}{l}\text { Como as escolas educam corpos nas práticas } \\
\text { pedagógicas? }\end{array}$ & 7 & 12 & 2014 \\
\hline DE SOUZA, L. P. & $\begin{array}{l}\text { Educação, gênero e raça: mapeando algumas } \\
\text { desigualdades }\end{array}$ & 7 & 12 & 2014 \\
\hline SILVA, M. A. C. & $\begin{array}{l}\text { Formação docente: do infinito ao particular! Narrativas } \\
\text { sobre gênero, raça e religião }\end{array}$ & 7 & 12 & 2014 \\
\hline SANTANA, A. M. & Gênero, sexualidade e educação: perspectivas em debate & 7 & 12 & 2014 \\
\hline BOGOSSIAN, T. & $\begin{array}{l}\text { "Já pensou Pedro com um cabelão de Maria Chiquinha! } \\
\text { Não combina, né?!". Geografia e gênero na educação } \\
\text { infantil }\end{array}$ & 7 & 12 & 2014 \\
\hline
\end{tabular}

Fonte: Elaboração dos autores (2019).

Uma vez definida a coleção de literatura, realizamos, num segundo movimento recursivo, a coleta de informações de cada estudo já selecionado. Nessa coleta, avaliamos os títulos, resumos e palavras-chave (COOPER, 2010). Neste movimento de pesquisa, destacamos as abordagens metodológicas que foram utilizadas com mais e com menos frequência nesses estudos. Como resultado desse procedimento, é possível verificar a categorização indicada no Quadro 2. 
Quadro 2 - Abordagens metodológicas utilizadas nos estudos levantados

\begin{tabular}{|l|l|}
\hline \multicolumn{1}{|c|}{ Abordagem } & \multicolumn{1}{c|}{ Estudo } \\
\hline Análise fílmica & Anjos e Cardoso (2014); Guzzi (2019) \\
\hline Análise de imagens & França e Ferrari (2016); Morais e Carvalho (2015); Santana (2014); \\
\hline Análise de narrativas & Santos e Feldens (2019) \\
\hline (Auto)Biografia, história de vida & Carvalho et al. (2017); Sarat e Campos (2014); Silva (2014) \\
\hline & $\begin{array}{l}\text { Bogossian (2014); Canotilho, Araujo e Oliveira (2014); Cardoso (2019); } \\
\text { Cruz (2014); Dias (2014); Dias e Menezes (2018); Dias et al. (2017); } \\
\text { Donato e Tonelli (2019); Dubet (2018); Ferreira (2014); Kaplan e Xavier } \\
\text { Ensaios/Pesquisa bibliográfica } \\
\text { (2018); Preinfalk-Fernández (2016); Santana et al. (2016); Thürler e } \\
\text { Santos (2014); Vieira e Coelho (2014) }\end{array}$ \\
\hline Estudos comparados & Kaplan e Xavier (2018) \\
\hline Pesquisa de campo & $\begin{array}{l}\text { Araújo e Barros (2017); Couto e Cruz (2017); Di Gregorio e Silva } \\
\text { (2014); Rodrigues e Faro (2019); Silva e Tavares (2019) }\end{array}$ \\
\hline Pesquisa documental & $\begin{array}{l}\text { Becker e Oliveira (2016); Costa e Macarro (2016); Galak (2017); } \\
\text { Rodrigues (2016); Santos e Lage (2017); Souza (2014) }\end{array}$ \\
\hline Pesquisa-ação & Silva Junior e lvenicki (2019) \\
\hline Pesquisa quantiqualitativa & Pinto, Carvalho e Rabay (2017) \\
\hline Pesquisa on-line & Porto e Galvão (2016) \\
\hline Pesquisa exploratória & Eugênio e Lima (2015) \\
\hline & Fonte: Elaboração dos autores (2019). \\
\hline
\end{tabular}

O Quadro 2 evidencia uma multiplicidade de abordagens com as quais as questões de gênero têm sido abordadas do ponto de vista investigativo no âmbito dos estudos publicados na REVTEE. No entanto, observa-se que existe uma tendência para a exploração de análise de narrativas, ensaios/pesquisas bibliográficas, pesquisas de campo e pesquisas documentais. Dentre essas, os estudos do tipo ensaio/pesquisa bibliográfica concentram 15 estudos, correspondendo a 37,5\% da amostra pesquisada.

Na sequência, realizamos a análise, síntese e interpretação dos estudos. A partir desses movimentos de análise, emergiram as seguintes categorias: a) Gênero e sexualidade como condicionantes da profissionalização dos sujeitos; b) Multiculturalismo e estudos interseccionais; c) Norma de gênero e corpo; d) Contribuições de pensadores/correntes teóricas para os estudos de gênero; e) Concepções acerca da mulher e seu papel social na contemporaneidade; f) Gênero, sexualidade e currículo; e g) Gênero, pessoas com deficiência, infância e família. Discutiremos acerca dessas categorias a seguir.

\section{a) Gênero e sexualidade como condicionantes da profissionalização dos sujeitos}

Dos 40 estudos levantados, quatro (10\%) se preocuparam em investigar, de forma central, as implicações do gênero e da sexualidade nos encaminhamentos e Educação \& Formação, Fortaleza, v. 5, n. 14, p. 150-175, maio/ago. 2020 
percursos profissionais dos sujeitos. Dubet (2018, p. 9), por exemplo, preocupou-se em "[...] explicar o paradoxo de que, apesar das meninas apresentarem melhores resultados escolares que os rapazes, elas se voltam aos cursos menos rentáveis, que as levam a posições profissionais menos favoráveis que a dos rapazes".

A esse respeito, segundo dados do Instituto Brasileiro de Geografia e Estatística (IBGE), na atualidade, as mulheres ganham menos do que os homens em todas as ocupações. Esse dado foi revelado a partir da Pesquisa Nacional por Amostra de Domicílios (PNAD - Contínua) de 2018, que, além disso, destacou que essa discrepância se acentua no caso das mulheres com faixa etária entre 40 e 49 anos, que recebem salários que correspondem a $79,4 \%$ dos salários recebidos por homens que ocupam os mesmos cargos que elas (IBGE, 2019).

O incômodo epistemológico emergente da conscientização atinentes às implicações dessa desigualdade social remeteu Pinto, Carvalho e Rabay (2017, p. 47) a analisarem "[...] como as relações de gênero condicionam as escolhas de cursos superiores de estudantes do ensino médio". A parir desse estudo, esses autores constataram que essa escolha não se dá de forma aleatória, mas condicionada pelas múltiplas variáveis que definem papéis sociais específicos para as mulheres e papéis sociais específicos para os homens.

Sarat e Campos (2014, p. 45) analisaram as "[...] trajetórias de duas professoras de Pedagogia de uma universidade pública localizada no interior da Região Centro-Oeste". A partir dessas análises, as autoras buscaram compreender como essas professoras universitárias "[...] vivenciaram/construíram concepções de gênero e sexualidade nas diversas relações interpessoais, nos espaços privado e público, uma vez que foram educadas e cuidadas para corresponderem aos comportamentos 'ditos' de meninas" (SARAT; CAMPOS, 2014, p. 45).

Quando a questão da condição feminina se assoma à uma orientação sexual declaradamente desviante da norma, o que se observa é a combinação de dispositivos socialmente excludentes. Nesse sentido, França e Ferrari (2016, p. 41) se preocuparam em problematizar as formas pelas quais os/as professores/as vão se constituindo como docentes homossexuais e discutir como esses/as "[...] vão se produzindo nas relações de poder, nas relações com o outro e, sobretudo, como se relacionam com os sujeitos e com a instituição escolar". 
A desigualdade de gênero entre homens e mulheres, evidenciada por estudos como os de Dubet (2018), Sarat e Campos (2014) e Pinto, Carvalho e Rabay (2017), numa sociedade machista, caminham pari passu com a luta para que os sujeitos que manifestem qualquer comportamento que seja associado à uma sexualidade desviante sejam paulatinamente excluídos e marginalizados. O estudo de França e Ferrari (2016) evidencia as dificuldades e a luta diária para que professores/as declaradamente homossexuais possam ascender e se manter nessa profissão.

\section{b) Multiculturalismo e estudos interseccionais}

Numa segunda linha de investigação, é possível agrupar os estudos de Eugênio e Lima (2015), Ferreira (2014), Kaplan e Xavier (2018), Rodrigues e Faro (2019), Silva (2014), Silva Junior e Ivenicki (2019) e Souza (2014). Sete estudos compõem essa categoria, o que representa $17,5 \%$ dos estudos levantados. Esses compartilham a preocupação com as implicações que as intersecções de marcadores sociais como gênero, raça, religião ou classe social trazem para o desenvolvimento dos sujeitos.

Estudos como os de Ferreira (2014), Silva (2014) e Souza (2014) se constituem em ensaios teóricos que investiram esforços em chamar a atenção para as características da sociedade em que vivemos e na qual questões de diferença, desigualdade, identidade, raça, classe, gênero, religião marcam a construção da identidade dos sujeitos, dentre os quais os homens. Nesse sentido, Silva Junior e Ivenicki (2019, p. 125, grifo nosso) enfocaram "[...] como o multiculturalismo pode oferecer subsídios para tematizar questões de sexualidades, raça, masculinidades e classe social em sala de aula".

Dentro de uma abordagem contemporânea e lançando luzes a um lócus de pesquisa educacional pouco explorado, Rodrigues e Faro (2019) buscaram compreender os processos não escolares que contribuem para a elaboração identitária das filhas e filhos de santo da Orixá lemanjá. Nesse caso, o trabalho aponta para campos de pesquisa que transcendem o escopo das instituições de ensino formal, mas nos quais há mecanismos que suportam o desenvolvimento, a aprendizagem, a formação e a liberdade dos sujeitos.

Kaplan e Xavier (2018 p. 111) buscaram "[...] compreender as diversas infâncias existentes". Para isso, tomaram as narrativas autobiográficas de mulheres 
negras de três países (Brasil, Argentina e Uruguai) sobre suas infâncias. Ao darem voz às mulheres negras, os autores passam a legitimar epistemologias singulares e pouco tradicionais no campo da pesquisa em Educação e da ciência em geral. Num movimento contrário, Eugênio e Lima (2015) evidenciaram, a partir da análise de conteúdos de livros didáticos de História dos anos iniciais do ensino fundamental que tratam sobre as questões do povo negro, que aqueles que falam sobre esse tema o fazem desde uma visão adro e eurocêntrica.

O que se evidencia dessas sínteses é a necessidade de se subverter essas epistemologias, em favor de que os sujeitos possam dizer a sua palavra (FREIRE, 2018). A educação, como ferramenta de empoderamento, está profundamente ligada à maneira como ela é concebida e oferecida, nesse sentido, evidencia-se a urgência da hegemonização de uma educação libertadora, de uma educação como prática de liberdade (HOOKS, 2013).

\section{c) Norma de gênero e corpo}

Estudos como os de Almeida (2017), Anjos e Cardoso (2014), Cardoso (2019), Dias (2014), Dias et al. (2017), Galak (2017), Guzzi (2019) e Thürler e Santos (2014) se preocuparam em problematizar as normas sociais que regulam os corpos e os oprimem de tal maneira que aquelas/es que ousam desobedecê-las podem pagar com suas próprias vidas. Esses sete estudos representam 17,5\% do total de artigos levantados.

Quando tratamos das questões de gênero e sua relação com a concepção de corpo, estamos tratando também da concepção de norma. Tais normas se apresentam nos adereços mais comuns, como destacado por Almeida (2017, p. 9), que percebeu o "[...] uniforme escolar como um aspecto essencial para se compreender o universo escolar e a cultura que o sustenta e o define". O uniforme escolar é apenas um dos inúmeros dispositivos de controle utilizados para padronizar os corpos, como nos chama a atenção Guzzi (2019) ao analisar o filme 21 Gramos, lançado em 2003 e dirigido pelo diretor mexicano Alejandro González Iñárritu. Também na perspectiva da análise fílmica, Anjos e Cardoso (2014) analisaram o filme Hanami - Cerejeiras em Flor, lançado em 2007 e dirigido por Doris Dörrie, e problematizaram a estabilidade das normas discursivas do "sexo". 
Cardoso (2019, p. 322) ressalta que "[...] há um processo de produção de mecanismos de normalização, onde há a separação de indivíduos 'normais' e 'anormais'”. Dentre as instituições nas quais esse processo é mais visível, destaca-se a escola. Essa é uma das principais "[...] instituições que atuam para a produção do sujeito moderno, do sujeito normalizado, a partir dos procedimentos disciplinares presentes nela" (CARDOSO, 2019, p. 322). Assim, a educação assume papel primordial. Essa, como parte de uma sociedade que discrimina, produz e reproduz desigualdades de gênero, constitui-se em um espaço generificado e, por isso, pode reproduzir a norma ou contribuir para subvertê-la.

A norma do gênero se expressa com mais clareza quando tomamos como exemplo o caso da disciplina de Educação Física. Segundo Donato e Tonelli (2019, p. 49), "[...] através das práticas de saber e poder da Educação Física sobre o corpo, ocorre uma de-subjetivação, dentro da qual condutas, comportamentos e hábitos acabam sendo naturalizados" Nas atividades desenvolvidas nas aulas de Educação Física é bastante comum a separação entre meninos e meninas. Esse tipo de segregação se pauta na concepção de que cada sexo tem suas atividades mais apropriadas. No limite, o que se obtém é um modelo que opera no sentido de "[...] educar os corpos de meninos e meninas para produzirem as diferenças" (DIAS, 2014, p. 105).

Nesse sentido, acerca dessa preocupação com a regulação dos corpos e da produção dessas diferenças, autores como Dias et al. (2017), Galak (2017) e Thürler e Santos (2014) investiram seus esforços em ensaios teóricos e pesquisas documentais para apontar alternativas de subversão da norma de gênero na busca por uma educação libertadora (FREIRE, 2018), uma educação que se expresse genuinamente como prática de liberdade (HOOKS, 2013).

\section{d) Contribuições de pensadores/correntes teóricas para os estudos de gênero}

Dentre os estudos levantados, chamou-nos a atenção a preocupação dos autores em tomarem como objetos de estudo pensadores ou correntes de pensamento que têm contribuído para o avanço dos estudos das questões de gênero. Quanto a essa categoria, podemos mencionar estudos como os de Becker e Oliveira (2016), Cardoso (2019), Cruz 
(2014), Dias e Menezes (2018) e Silva Junior e Ivenicki (2019). Trata-se de cinco estudos que representam $12,5 \%$ do total de artigos levantados.

Nessa categoria, é possível destacar o estudo de Cardoso (2019, p. 319), que tomou como objeto "[...] a contribuição da teorização de Michel Foucault para a discussão sobre gênero, sexualidade e educação"; o estudo de Silva Junior e Ivenicki (2019, p. 125), que investigaram "[...] como o multiculturalismo pode oferecer subsídios para tematizar questões de sexualidades, raça, masculinidades e classe social em sala de aula"; o estudo de Dias e Menezes (2018, p. 37), que problematizaram "[...] as potencialidades de uma pedagogia e um currículo queer na escola"; o estudo de Becker e Oliveira (2016, p. 163), que investiram na desconstrução da categoria gênero presente na Lei Maria da Penha, "[...] no sentido deleuziano/guattariano"; bem como o estudo de Cruz (2014, p. 15), que investigou uma "[...] epistemologia feminista à ciência e à pesquisa nas ciências humanas e sociais, particularmente na área da educação".

O investimento dos autores desses estudos convergiu no sentido de produzir um corpo teórico capaz de dar conta dos fenômenos emergentes das relações entre gênero e Educação no sentido de uma educação libertadora (FREIRE, 2018; HOOKS, 2013).

\section{e) Concepções acerca da mulher e seu papel social na contemporaneidade}

Para a composição dessa categoria, contribuíram os estudos de Araújo e Barros (2017), Canotilho, Araujo e Oliveira (2014), Carvalho et al. (2017), Morais e Carvalho (2015), Sarat e Campos (2014), Porto e Galvão (2016), Santos e Feldens (2019) e Silva e Tavares (2019). Esses sete estudos representam 17,5\% do total de estudos levantados e convergem para um conjunto de investigações que analisaram "[...] a produção discursiva acerca da mulher na escola contemporânea" (SANTOS; FELDENS, 2019 , p. 379) e para além do espaço escolar. Esse material enfocou a análise de mulheres contemporâneas, empoderadas, que, já conscientes de sua condição oprimida, não se conformaram com os grilhões que o machismo Ihes quis/quer impor. É o caso, por exemplo, do estudo de autores como Silva e Tavares (2019, p. 41), que "[...] analisaram a participação de mulheres nas ocupações realizadas em 2016 na Universidade Federal de Pernambuco"; mulheres que compõem o movimento estudantil, que levantam a voz contra as injustiças e que lutam por uma sociedade mais igualitária. 
Esses autores, ao problematizarem a participação de mulheres universitárias nas ocupações estudantis de 2016, concluíram que "[...] a vivência de práticas democráticas e o ambiente propício à discussão dos direitos humanos fomentam uma potencial transformação nas práticas e nas relações" (SILVA; TAVARES, 2016, p. 41). Nesse sentido, as ocupações do ano de 2016 se configuraram como um importante momento para que as alunas tomassem a palavra, dissessem a sua palavra, atuassem como protagonistas de um processo político e se identificassem com questões relacionadas ao feminismo (FREIRE, 2018).

Nessa mesma linha de pensamento, o estudo de Porto e Galvão (2016) apresenta o contexto da "Marcha das Vadias da cidade de Natal", Rio Grande do Norte (2011, 2015), e o significa como um campo político que deu visibilidade aos feminismos locais atuantes naquela cidade e naquele estado. Já com o olhar mais voltado para movimentos menos massivos, Araújo e Barros (2017, p. 173) analisaram "[...] alguns dos traços principais dos usos do tempo, por parte das mulheres académicas, identificando algumas das suas implicações para a política académica e científica a nível institucional". De modo análogo, Morais e Carvalho (2015, p. 235) analisaram, "[...] através das narrativas de três acadêmicas feministas de uma universidade federal nordestina, suas contribuições para a institucionalização dos estudos de gênero".

Apesar dos avanços identificados, é patente que o combate às desigualdades de gênero deve resistir e se intensificar para que possamos produzir uma sociedade igualitária. Nesse sentido, estudos como os de Araújo e Barros (2017), Morais e Carvalho (2015), Porto e Galvão (2016) e Silva e Tavares (2019) retratam cenários de luta tendo como protagonistas mulheres em seus movimentos de resistência e luta, as quais também arregimentaram movimentos exitosos.

Os dois primeiros estudos retrataram movimentos de luta de ampla repercussão nacional, e os outros dois, não menos importantes, destacaram a luta diária das mulheres, que, em seu fazer laboral, ao não se conformarem com a realidade (im)posta, travam disputas de poder com o machismo e arregimentam ganhos para a causa feminina. Paradoxalmente a esse cenário exitoso, Canotilho, Araújo e Oliveira (2014, p. 91) lançaram luzes aos "[...] constrangimentos no acesso das mulheres aos cargos de decisão e às estruturas de democracia formal". Uma mulher ocupar um lugar de poder 
nessa sociedade machista já é, por si só, um grande desafio, mas se manter nesses lugares de poder é uma batalha diária.

Carvalho et al. (2017, p. 163) enfocaram "[...] as trajetórias dos centros de estudos de gênero afiliados à Rede Feminista de Estudos de Gênero do Norte / Nordeste (REDOR) e de seus fundadores". O último estudo que compõe essa categoria é de autoria de Sarat e Campos (2014, p. 45), que apresentam "[...] reflexões construídas nas trajetórias de duas professoras de Pedagogia de uma universidade pública localizada no interior da Região Centro Oeste". A preocupação desse estudo se coaduna com a preocupação dos estudos supracitados nesta categoria, uma vez que esse buscou "[...] conhecer e compreender como [essas mulheres] vivenciaram/construíram concepções de gênero e sexualidade nas diversas relações interpessoais, nos espaços privado e público" (SARAT; CAMPOS, 2014, p. 45).

Essa questão se justifica porque as mulheres que conseguiram resistir à opressão machista que diz a elas diariamente que seu lugar é em casa, sob o mando do pai, do irmão, do marido, ou equivalente, precisam redobrar sua força de trabalho para assumir os desafios laborais dentro e fora de casa. Segundo Sarat e Campos (2014, p. 45), essas mulheres, assim como tantas outras, "[...] foram educadas e cuidadas para corresponderem aos comportamentos 'ditos' de meninas, conforme padrões sociais e históricos dominantes", as quais, ainda que ousem ocupar espaços laborais fora de casa, os afazeres domésticos continuarão a pesar sobre os seus ombros. É por não se conformarem em ocupar o lugar de oprimidas ad infinitum, mas em movimento coletivo de conscientização, que elas têm se empoderado, se fortalecido, tomado a palavra e se libertado (FREIRE, 2018).

\section{f) Gênero, sexualidade e currículo}

Os estudos que nos auxiliaram a compor esta categoria foram os de Couto e Cruz (2017), Dias e Menezes (2018), Rodrigues (2016) e Santos e Lage (2017). Trata-se de quatro estudos que têm como foco a presença de questões de gênero e sexualidade no currículo escolar brasileiro e também no currículo escolar europeu (RUDD; GOODSON, 2016; ULJENS, 2016). Esse volume de material corresponde a $10 \%$ dos estudos levantados. 
De modo comum, esses estudos buscaram "[...] identificar no currículo a ausência do gênero" (COUTO; CRUZ, 2017, p. 249) ou "[...] investigar o que indicam os conteúdos programáticos [...], em relação às questões de gênero e diversidade sexual" (SANTOS; LAGE, 2017, p. 69). Tais pesquisas sinalizam para a preocupação acerca da presença e da ausência de temas relacionados às questões de gênero no currículo escolar.

Dias e Menezes (2017, p. 37) lançaram mão das "[...] potencialidades de uma pedagogia e um currículo queer na escola", como alternativa para uma formação libertadora e que valorize os sujeitos em suas mais altas potencialidades. É por meio do currículo que a instituição escolar revela e executa sua forma de ver e de pensar 0 mundo e também uma das formas pelas quais o governo exerce o biopoder e a governamentalidade (FOUCAULT, 1993). Partindo desse pressuposto, "[...] estranhar o currículo da escola, passar a ser uma das inovações que a pedagogia queer propõe a a@s estudantes e professor@s hoje" (DIAS; MENEZES, 2017, p. 37).

Ao enfocar a questão da presença de temas de educação sexual no currículo da Costa Rica, Preinfalk-Fernández (2016, p. 103) traçou um panorama do "[...] proceso histórico-evolutivo de la educación sexual en el sistema educativo costarricense". Costa e Macarro (2016, p. 111) apresentaram uma análise "[...] de cómo el tema educativo se coloca en la Ley Orgánica 01/2004, de 28 de diciembre, que trata de las medidas de protección integral contra la violencia de género en España". Já Rodrigues (2016) investigou um relatório que foi aprovado em setembro de 2015 e que foi solicitado pelo Parlamento Europeu à Comissão dos Direitos das Mulheres e da Igualdade dos Gêneros. Esse documento pretendia assegurar uma educação democrática e a educação para a igualdade dos gêneros pela via do currículo.

O que se verifica nesses três estudos que trazem à baila documentos e diretrizes curriculares internacionais que tratam de questões de gênero é que, nesse sentido, a realidade global não é assim tão distante da realidade brasileira e que a disputa entre uma formação progressista e uma formação conservadora está presente nos debates curriculares mundiais.

De acordo com Santos e Lage (2017, p. 69), existe um silenciamento, por exemplo, "[...] sobre transexualidade e cidadania de pessoas trans". Segundo Silva (2000, p. 89), "[...] a diferença não é uma característica natural: ela é discursivamente produzida". Portanto, é por meio dos discursos que produzimos e reproduzimos as diferenças que 
podem gerar conflitos e desestabilizar paradigmas tradicionais, pois "[...] são os próprios valores da civilização ocidental [...] que estão em risco quando o estilo de vida dos homossexuais, por exemplo, se torna matéria curricular" (SILVA, 2000, p. 92).

\section{g) Gênero, pessoas com deficiência, infância e família}

Para a composição desta categoria, contribuíram os estudos de Bogossian (2014), Carvalho et al. (2017), Di Gregorio e Silva (2014), Kaplan e Xavier (2018), Santana (2014), Santana et al. (2016) e Vieira e Coelho (2014). Esses sete estudos representam $17,5 \%$ do material levantado, os quais enfatizam o fato de gênero ser uma categoria que constitui todo e qualquer sujeito.

Acerca dessa questão, Kaplan e Xavier (2018, p. 111), ao captarem narrativas autobiográficas reminiscentes de "[...] diversas infâncias existentes, descritas em três países Brasil, Argentina e Uruguai, no período de 1930 a 1940, formalizaram uma compreensão da imagem do negro elaborada pela escrita de autoras mulheres". Aqui nos chama a atenção o fato de esses autores terem pesquisado a infância de meninas negras a partir dessas quando em idade adulta.

Santana et al. (2016, p. 63) buscaram "[...] compreender a relação entre educação, gênero e sexualidade e seus desdobramentos para a compreensão das relações de gênero no lócus da educação infantil". Já Bogossian (2014, p. 169) refletiu a respeito da "[...] desigualdade de gênero presente em uma instituição de Educação Infantil no município de Niterói, no Estado do Rio de Janeiro". Desses três, observamos que, apesar de esses estudos terem como foco a relação entre a infância e as questões de gênero, não tomaram como participantes as próprias crianças.

Por estarmos inseridos numa sociedade machista e vivermos na contemporaneidade uma onda conservadora, ao realizar pesquisas sobre gênero com crianças, é possível ter graves problemas - na investigação e para além dela. Essa pode ser uma justificativa para o fato de os estudos que analisaram as relações entre gênero e infância não terem trabalhado com as próprias crianças.

Essa onda conservadora e o populismo de extrema direita, ascendente no mundo inteiro, têm como um dos seus reflexos um clima de hostilidade contra os estudos sobre gênero, e isso se reflete diretamente na relação entre escola e família. 
Nesse sentido, Di Gregorio e Silva (2014, p. 79) apontam "[...] possibilidades de diálogo entre o tema Educação, Gênero, Diversidade Sexual e Direitos Humanos no lócus da Família e da Escola". O foco desses pesquisadores é a "[...] sexualidade não heterossexual e seus desafios desde a orientação na família e a construção das identidades de gênero no cenário escolar/social" (DI GREGORIO; SILVA, 2014, p. 79). O mesmo se aplica para o caso tratado por Santana (2014), que enfocou a questão da mulher lésbica na relação homoafetiva.

Dentre os estudos que compõem esta categoria que envolve a infância, a família e as pessoas com deficiência, o tema menos frequente foi o último. Ao lançar luzes às questões de gênero e sexualidade de jovens com deficiência intelectual, Vieira e Coelho (2014) não usaram meias palavras para atestar que pessoas com deficiência são também pessoas gendrificadas. A invisibilização do gênero e da sexualidade desses sujeitos é reflexo da invisibilização desses sujeitos como um todo. Para a superação desse quadro, é imprescindível uma educação libertadora radical, uma educação como prática de liberdade (FREIRE, 2018; HOOKS, 2013).

\section{Considerações finais}

Constatamos que a produção científica que abordou questões de gênero no âmbito da REVTEE, no período de 2014 a 2019, evidenciou que esse tema, por si só, constitui-se num marcador social que condiciona as escolhas e as carreiras profissionais dos sujeitos, mas que, quando analisado em intersecção com questões de raça, religião e classe, potencializa ideologias desumanizadoras que oprimem, marginalizam, excluem e invisibilizam aquelas e aqueles em cujos corpos estão revelados traços que os façam ser identificados como desviantes da norma.

Por outro lado, ressaltamos a presença de uma contracorrente que tem conferido força e empoderamento àquelas/es que têm sido silenciadas/os. São exemplos dessa contracorrente os movimentos de rua que lutam pela igualdade de gênero, como a Marcha das Vadias e a luta cotidiana das mulheres contra todas as formas, sutis e descaradas, pelas quais se manifesta o machismo.

Evidenciamos que, mesmo nos estudos que enfocaram a relação entre gênero e infância, nenhum deles considerou as falas das próprias crianças. Do mesmo modo, a 
escola e a família, como instituições irmãs no compromisso com a formação das crianças, ao tratar sobre questões de gênero, por aspectos de base moral conservadora, têm rivalizado em polos antagônicos. Além disso, pouco se discute acerca de questões de "gênero e pessoas com deficiência". Esse panorama revela um quadro sintomático do levante da onda conservadora que insiste em negar a existência daquelas/es desviantes da norma.

Além dos temas que foram pouco discutidos ou discutidos de forma indireta, chamaram-nos a atenção os temas que não foram discutidos nos estudos levantados, por exemplo: a relação entre gênero e velhice; as políticas de prevenção e tratamento do HIV em ambientes formais e não formais de ensino; a pornografia de vingança em ambientes escolares; a medicalização dos comportamentos desviantes conduzidos a partir da escola; as polêmicas sobre o uso do banheiro por pessoas trans ou travestis, além de tantos outros temas latentes por investigações.

Nesse sentido, é possível sustentar que as relações de gênero são compreendidas como construção social, histórica e cultural, sendo a escola um dos espaços privilegiados para a sua abordagem. Os estudos levantados apontam elementos de originalidade, seja pelo próprio objeto, pelo lócus da investigação, pelo referencial teórico adotado, pela abordagem metodológica empregada ou pela ousadia com que os resultados foram apresentados.

Ainda que muito distante de uma sociedade igualitária, os estudos sistematizados nesta pesquisa indicam que a luta de todas/os que sentem na carne a opressão contra seu gênero tem surtido efeito e que a resistência precisa continuar e ser cada vez mais fortalecida. Na convergência desses estudos, percebemos que é urgente e necessária a luta diária por políticas públicas que subsidiem ações voltadas para a construção de uma sociedade combativa a qualquer ideologia que negue a humanidade dos seres humanos.

\section{Referências}

ALMEIDA, W. R. A. Uniforme escolar e uniformização dos corpos. Revista Tempos e Espaços em Educação, São Cristóvão, v. 10, n. 22, p. 9-22, 2017. Disponível em: https://seer.ufs.br/index.php/revtee/article/view/6134. Acesso em: 3 jan. 2020. DOI: https://doi.org/10.20952/revtee.v10i22.6134. 
ANJOS, J. P.; CARDOSO, L. R. Hanami ou corpos fogem, vazam, escapam... Revista Tempos e Espaços em Educação, São Cristóvão, v. 7, n. 14, p. 69-78, 2014. Disponível em: https://seer.ufs.br/index.php/revtee/article/view/2953. Acesso em: 3 jan. 2020. DOI: https://doi.org/10.20952/revtee.v0i0.2953.

ARAÚJO, E.; BARROS, V. "Modo Deadline": uma análise sobre o tempo das mulheres académicas. Revista Tempos e Espaços em Educação, São Cristóvão, v. 10, n. 22, p. 173-186, 2017. Disponível em: https://seer.ufs.br/index.php/revtee/article/view/6440. Acesso em: 3 jan. 2020. DOI: https://doi.org/10.20952/revtee.v10i22.6440.

BECKER, S.; OLIVEIRA, E. A. Educação e direitos para (in)humanos? Desafios e reflexões sobre os dilemas de LGBTs perante o discurso jurídico brasileiro. Revista Tempos e Espaços em Educação, São Cristóvão, v. 9, n. 19, p. 163-180, 2016. Disponível em: https://seer.ufs.br/index.php/revtee/article/view/5603. Acesso em: 3 jan. 2020. DOI: https://doi.org/10.20952/revtee.v9i19.5603.

BOGOSSIAN, T. "Já pensou Pedro com um cabelão de Maria Chiquinha! Não combina, né?!". Geografia e gênero na educação infantil. Revista Tempos e Espaços em Educação, São Cristóvão, v. 7, n. 12, p. 169-186, 2014. Disponível em: https://seer.ufs.br/index.php/revtee/article/view/2963. Acesso em: 3 jan. 2020. DOI: https://doi.org/10.20952/revtee.v0i0.2963.

CANOTILHO, A. P.; ARAUJO, N. F.; DE OLIVEIRA, S. M. T. A contribuição da escola para a emancipação das mulheres. Revista Tempos e Espaços em Educação, São Cristóvão, v. 7, n. 14, p. 91-102, 2014. Disponível em: https://seer.ufs.br/index.php/rev tee/article/view/2957. Acesso em: 3 jan. 2020. DOI: https://doi.org/10.20952/revtee. v0i0.2957.

CARDOSO, H. M. Gênero, sexualidade e escola: contribuições da teorização de Foucault. Revista Tempos e Espaços em Educação, São Cristóvão, v. 11, n. 1, p. 319332, 2019. Disponível em: https://seer.ufs.br/index.php/revtee/article/view/9652. Acesso em: 3 jan. 2020. DOI: https://doi.org/10.20952/revtee.v11i01.9652.

CARDOSO, H. M.; DIAS, A. F. Representações sobre corpo, gênero e sexualidades de estudantes das licenciaturas do Instituto Federal de Sergipe, campus Aracaju. Práxis Educacional, Vitória da Conquista, v. 13, n. 24, p. 76-94, 2016. Disponível em: http://periodicos2.uesb.br/index.php/praxis/article/view/930. Acesso em: 6 jan. 2020. DOI: https://doi.org/10.22481/praxis.v13i24.930.

CARVALHO, M. E. P. et al. Origins and challenges of gender studies centers in higher education in NorthERN and Northeastern Brazil. Revista Tempos e Espaços em Educação, São Cristóvão, v. 10, n. 21, p. 163-176, 2017. Disponível em: https://seer.ufs.br/index.php/revtee/article/view/6340. Acesso em: 3 jan. 2020. DOI: https://doi.org/10.20952/revtee.v10i21.6340. 
COOPER, H. Research synthesis and meta-analysis: a step-by-step approach. 3. ed. Thousand Oaks: Sage, 2010.

COSTA, P. R. S. M.; MACARRO, M. J. M. Los aspectos educativos de la Ley Orgánica $01 / 2004$ de 28 de diciembre, de medidas de protección integral contra la violencia de género. Revista Tempos e Espaços em Educação, São Cristóvão, v. 9, n. 20, p. 111-120, 2016. Disponível em: https://seer.ufs.br/index.php/revtee/article/view/5900. Acesso em: 3 jan. 2020. DOI: https://doi.org/10.20952/revtee.v9i20.5900.

COUTO, A. S.; CRUZ, M. H. S. Inserção de gênero no currículo de História e a formação para o trabalho docente. Revista Tempos e Espaços em Educação, São Cristóvão, v. 10, n. 23, p. 249-262, 2017. Disponível em: https://seer.ufs.br/index.php/revtee/article/ view/6764. Acesso em: 3 jan. 2020. DOI: https://doi.org/10.20952/revtee.v10i23.6764.

CRUZ, M. H. S. A crítica feminista à ciência e contribuição à pesquisa nas Ciências Humanas. Revista Tempos e Espaços em Educação, São Cristóvão, v. 7, n. 14, p. 1528, 2014. Disponível em: https://seer.ufs.br/index.php/revtee/article/view/2949. Acesso em: 3 jan. 2020. DOI: https://doi.org/10.20952/revtee.v0i0.2949.

DIAS, A. F. Como as escolas educam corpos nas práticas pedagógicas?. Revista Tempos e Espaços em Educação, São Cristóvão, v. 7, n. 12, p. 103-112, 2014. Disponível em: https://seer.ufs.br/index.php/revtee/article/view/2958. Acesso em: 3 jan. 2020. DOI: https://doi.org/10.20952/revtee.v0i0.2958.

DIAS, A. F. et al. Schooling and subversions of gender. Revista Tempos e Espaços em Educação, São Cristóvão, v. 10, n. 22, p. 83-92, 2017. Disponível em: https://seer.ufs.br/index.php/revtee/article/view/6433. Acesso em: 3 jan. 2020. DOI: https://doi.org/10.20952/revtee.v10i22.6433.

DIAS, A. F.; AMORIM, S. Body, gender and sexuality in teacher training: a metaanalysis. Educação em Revista, Curitiba, n. 56, p. 193-206, 2015. Disponível em: http://www.scielo.br/scielo.php?script=sci_arttext\&pid=S0104-40602015000200193\&lng= en\&nrm=iso. Acesso em: 6 jan. 2020. DOI: http://dx.doi.org/10.1590/0104-4060.40998.

DIAS, A. F.; MENEZES, C. A. A. Que inovação pedagógica a pedagogia queer propõe ao currículo escolar?. Revista Tempos e Espaços em Educação, São Cristóvão, v. 10, n. 23, p. 37-48, 2017. Disponível em: https://seer.ufs.br/index.php/revtee/article/view/ 7443. Acesso em: 3 jan. 2020. DOI: https://doi.org/10.20952/revtee.v10i23.7443.

DIAS, A. F.; OLIVEIRA, D. A. As abordagens de corpo, gênero e sexualidades no projeto político-pedagógico em um Colégio Estadual de Aracaju, SE. Holos, Natal, v. 3, p. 259271, 2015. Disponível em: https://doi.org/10.22478/ufpb.2359-7003.2018v27n2.24814. Acesso em: 10 jan. 2020. Disponível em: http://www2.ifrn.edu.br/ojs/index.php/holos/ar ticle/view/3084. Acesso em: 06 jan. 2020. DOI: https://doi.org/10.15628/holos.2015.3084.

DIAS, A. F.; OLIVEIRA, D. A.; SANTOS, M. S. Uma revisão sistematizada da produção do conhecimento sobre corpo, gênero, sexualidades na educação. Revista Temas em 
Educação, João Pessoa, v. 27, n. 2, p. 119-133, 2018. Disponível em: https://doi.org/10.22478/ufpb.2359-7003.2018v27n2.24814. Acesso em: 10 jan. 2020.

DI GREGORIO, M. F.; SILVA, K. N. Gênero e sexualidade no lócus família/escola: incursões deflagradas à não heterossexualidade e os desafios para a cidadania reconhecida. Revista Tempos e Espaços em Educação, São Cristóvão, v. 7, n. 12, p. 7990, 2014. Disponível em: https://seer.ufs.br/index.php/revtee/article/view/2954. Acesso em: 3 jan. 2020. DOI: https://doi.org/10.20952/revtee.v0i0.2954.

DONATO, A.; TONELLI, L. A resistência do corpo. Revista Tempos e Espaços em Educação, São Cristóvão, v. 12, n. 28, p. 49-62, 2019. Disponível em: https://seer.ufs.br/index.php/revtee/article/view/10164. Acesso em: 3 jan. 2020. DOI: https://doi.org/10.20952/revtee.v12i28.10164.

DUBET, F. A escola "embaraçada" com a educação mista. Revista Tempos e Espaços em Educação, São Cristóvão, v. 11, n. 25, p. 9-20, 2018. Disponível em: https://seer.ufs.br/index.php/revtee/article/view/8379. Acesso em: 3 jan. 2020. DOI: https://doi.org/10.20952/revtee.v11i25.8379.

EUGÊNIO, B. G.; LIMA, A. O. Imagens de negros e negras no livro didático de História dos anos iniciais do ensino fundamental. Revista Tempos e Espaços em Educação, São Cristóvão, v. 8, n. 16, p. 247-256, 2015. Disponível em: https://seer.ufs.br/index.php/rev tee/article/view/3964. Acesso em: 3 jan. 2020. DOI: https://doi.org/10.20952/revtee.v0i0. 3964.

FERREIRA, M. M. Relações de classe e gênero na escola: revisitando conceitos de igualdade, desigualdade, diferença, classe e gênero. Revista Tempos e Espaços em Educação, São Cristóvão, v. 7, n. 14, p. 57-68, 2014. Disponível em: https://seer.ufs.br/index.php/revtee/article/view/2952. Acesso em: 3 jan. 2020. DOI: https://doi.org/10.20952/revtee.v0i0.2952.

FIGUEIREDO FILHO, D. B. et al. O que é, para que serve e como se faz uma meta-análise?. Revista Teoria \& Pesquisa, São Carlos, v. 23, n. 2, p. 205-228, 2014.

FOUCAULT, M. Microfísica do poder. 11. ed. Rio de Janeiro: Graal, 1993.

FRANÇA, F. G. R.; FERRARI, A. Mais do que professores/as, professores/as homossexuais na escola. Revista Tempos e Espaços em Educação, São Cristóvão, v. 9, n. 20, p. 41-52, 2016. Disponível em: https://seer.ufs.br/index.php/revtee/article/view/ 5894. Acesso em: 3 jan. 2020. DOI: https://doi.org/10.20952/revtee.v9i20.5894.

FREIRE, P. Pedagogia do oprimido. 65. ed. Rio de Janeiro: Paz e Terra, 2018.

GALAK, E. Pedagogías del cuerpo y del carácter en la "Revista de Educación" durante la gobernación de José Luís Cantilo (Buenos Aires, 1922-1926). Revista Tempos e Espaços em Educação, São Cristóvão, v. 10, n. 21, p. 149-162, 2017. Disponível em: 
https://seer.ufs.br/index.php/revtee/article/view/6339. Acesso em: 3 jan. 2020. DOI: https://doi.org/10.20952/revtee.v10i21.6339.

GUZZI, J. 21 Gramos: el amor como epifenómeno de la tensión cuerpo-alma. Revista Tempos e Espaços em Educação, São Cristóvão, v. 12, n. 29, p. 213-226, 2019. Disponível em: https://seer.ufs.br/index.php/revtee/article/view/9514. Acesso em: 3 jan. 2020. DOI: https://doi.org/10.20952/revtee.v12i29.9514.

HOOKS, b. Ensinando a transgredir: a educação como prática da liberdade. São Paulo: Martins Fontes, 2013.

IBGE - Instituto Brasileiro de Geografia e Estatística. Diferença do rendimento do trabalho de mulheres e homens nos grupos ocupacionais: Pesquisa Nacional por Amostra de Domicílios (PNAD) Contínua-2018. Brasília, DF: Agência de Notícias, 2019.

KAPLAN, C. V.; XAVIER, N. R. As infâncias na literatura latino-americana: quais os lugares da menina e da mulher negras?. Revista Tempos e Espaços em Educação, São Cristóvão, v. 11, n. 25, p. 111-126, 2018. Disponível em: https://seer.ufs.br/index.php/ revtee/article/view/8797. Acesso em: 3 jan. 2020. DOI: https://doi.org/10.20952/revtee. v11i25.8797.

MORAIS, A. B. A.; CARVALHO, M. E. P. Institucionalização dos estudos de gênero na universidade: uma análise a partir de narrativas de acadêmicas feministas. Revista Tempos e Espaços em Educação, São Cristóvão, v. 8, n. 17, p. 235-236, 2015. Disponível em: https://seer.ufs.br/index.php/revtee/article/view/4526. Acesso em: 3 jan. 2020. DOI: https://doi.org/10.20952/revtee.v8i17.4526.

PINTO, É. J. S.; CARVALHO, M. E. P.; RABAY, G. As relações de gênero nas escolhas de cursos superiores. Revista Tempos e Espaços em Educação, São Cristóvão, v. 10, n. 22, p. 47-58, 2017. Disponível em: https://seer.ufs.br/index.php/revtee/article/ view/6173. Acesso em: 3 jan. 2020. DOI: https://doi.org/10.20952/revtee.v10i22.6173.

PORTO, R.; GALVÃO, F. D. De Slutwalk à Marcha das Vadias: o imperativo dos feminismos em Natal (RN). Revista Tempos e Espaços em Educação, São Cristóvão, v. 9, n. 19, p. 147-162, 2016. Disponível em: https://seer.ufs.br/index.php/revtee/ article/view/5602. Acesso em: 3 jan. 2020. DOI: https://doi.org/10.20952/revtee.v9i19.5602.

PREINFALK-FERNÁNDEZ, M. L. La Educación sexual en el sistema educativo formal costarricense. Revista Tempos e Espaços em Educação, São Cristóvão, v. 9, n. 19, p. 103-112, 2016. Disponível em: https://seer.ufs.br/index.php/revtee/article/view/5599. Acesso em: 3 jan. 2020. DOI: https://doi.org/10.20952/revtee.v9i19.5599.

RIOS, P. P.; CARDOSO, H. M.; DIAS, A. F. Concepções de gênero e sexualidade d@s docentes do curso de licenciatura em Pedagogia: por um currículo Queer. Educação \& Formação, Fortaleza, v. 3, n. 8, p. 98-117, 2018. Disponível em: https://revistas.uece.br/index.php/redufor/article/view/272. Acesso em: 10 jan. 2020. DOI: https://doi.org/10.25053/redufor.v3i8.272. 
RODRIGUES, D. S.; FARO, L. C. A. Entre fronteiras semoventes: a constituição do feminino das filhas de lemanjá. Revista Tempos e Espaços em Educação, São Cristóvão, v. 12, n. 29, p. 61-80, 2019. Disponível em: https://seer.ufs.br/index.php/ revtee/article/view/11022. Acesso em: 3 jan. 2020. DOI: https://doi.org/10.20952/revtee. v12i29.11022.

RODRIGUES, L. Transgredir para empoderar: o empoderamento das jovens mulheres pela educação. Revista Tempos e Espaços em Educação, São Cristóvão, v. 9, n. 18, p. 91-98, 2016. Disponível em: https://seer.ufs.br/index.php/revtee/article/view/4967. Acesso em: 3 jan. 2020. DOI: https://doi.org/10.20952/revtee.v9i18.4967.

RUDD, T.; GOODSON, I. F. Refraction as a tool for understanding action and educational orthodoxy and transgression. Revista Tempos e Espaços em Educação, São Cristóvão, v. 9, n. 18, p. 99-110, 2016. Disponível em: https://seer.ufs.br/index.php/revtee/article/ view/4968. Acesso em: 21 jan. 2020. DOI: https://doi.org/10.20952/revtee.v9i18.4968.

SANTANA, A. M. Gênero, sexualidade e educação: perspectivas em debate. Revista Tempos e Espaços em Educação, São Cristóvão, v. 7, n. 12, p. 151-168, 2014. Disponível em: https://seer.ufs.br/index.php/revtee/article/view/2962. Acesso em: 3 jan. 2020. DOI: https://doi.org/10.20952/revtee.v0i0.2962.

SANTANA, J. V. J. et al. Constituindo gêneros: sobre a produção de masculinidades e feminilidades na educação infantil. Revista Tempos e Espaços em Educação, São Cristóvão, v. 9, n. 20, p. 63-80, 2016. Disponível em: https://seer.ufs.br/index.php/ revtee/article/view/5896. Acesso em: 3 jan. 2020. DOI: https://doi.org/10.20952/revtee. v9i20.5896.

SANTOS, A. C.; FELDENS, D. G. Vozes do triunfo: narrativas de si de professoras da educação básica. Revista Tempos e Espaços em Educação, São Cristóvão, v. 11, n. 1, p. 379-392, 2019. Disponível em: https://seer.ufs.br/index.php/revtee/article/view/9666. Acesso em: 3 jan. 2020. DOI: https://doi.org/10.20952/revtee.v11i01.9666.

SANTOS, É. S.; LAGE, A. C. Gênero e diversidade sexual na educação básica: um olhar sobre o componente curricular Direitos Humanos e Cidadania da rede de ensino de Pernambuco. Revista Tempos e Espaços em Educação, São Cristóvão, v. 10, n. 22, p. 69-82, 2017. Disponível em: https://seer.ufs.br/index.php/revtee/article/view/6042. Acesso em: 3 jan. 2020. DOI: https://doi.org/10.20952/revtee.v10i22.6042.

SANTOS, W. J.; SILVA, I. P. Revisão acerca dos temas alfabetização científica e ensino por investigação. Educa: Revista Multidisciplinar em Educação, Porto Velho, v. 5, n. 12, p. 138-150, 2018. Disponível em: http://www.periodicos.unir.br/index.php/educa/article/ view/3344. Acesso em: 22 jan. 2020. DOI: http://dx.doi.org/10.26568/23592087.2018.3344.

SARAT, M.; CAMPOS, M. I. Gênero, sexualidade e infância: (con)formando meninas. Revista Tempos e Espaços em Educação, São Cristóvão, v. 7, n. 14, p. 45-56, 
2014. Disponível em: https://seer.ufs.br/index.php/revtee/article/view/2951. Acesso em: 3 jan. 2020. DOI: https://doi.org/10.20952/revtee.v0i0.2951.

SILVA JUNIOR, P. M.; IVENICKI, A. Entre sexualidades, masculinidades e raça: contribuições do multi/interculturalismo para a prática pedagógica. Revista Tempos e Espaços em Educação, São Cristóvão, v. 12, n. 29, p. 125-144, 2019. Disponível em: https://seer.ufs.br/index.php/revtee/article/view/9326. Acesso em: 3 jan. 2020. DOI: https://doi.org/10.20952/revtee.v12i29.9326.

SILVA, I. P.; MERCADO, L. P. L. Revisão sistemática de literatura acerca da experimentação virtual no ensino de Física. Ensino \& Pesquisa, União da Vitória, v. 17, n. 1, p. 49-77, 2019. Disponível em: http://periodicos.unespar.edu.br/index.php/ensinoe pesquisa/article/view/2381. Acesso em: 22 jan. 2020.

SILVA, M. A. C. Formação docente: do infinito ao particular! Narrativas sobre gênero, raça e religião. Revista Tempos e Espaços em Educação, São Cristóvão, v. 7, n. 12, p. 125-136, 2014. Disponível em: https://seer.ufs.br/index.php/revtee/article/view/2960. Acesso em: 3 jan. 2020. DOI: https://doi.org/10.20952/revtee.v0i0.2960.

SILVA, M. M. T.; TAVARES, C. Mulheres na luta: participação de mulheres nas ocupações de 2016 na Universidade Federal de Pernambuco. Revista Tempos e Espaços em Educação, São Cristóvão, v. 11, n. 27, p. 41-60, 2018. Disponível em: https://seer.ufs.br/index.php/revtee/article/view/7409. Acesso em: 3 jan. 2020. DOI: https://doi.org/10.20952/revtee.v11i27.7409.

SILVA, T. T. Documentos de identidade: uma introdução às teorias do currículo. São Paulo: Autêntica, 2000.

SOUZA, L. P. Educação, gênero e raça: mapeando algumas desigualdades. Revista Tempos e Espaços em Educação, São Cristóvão, v. 7, n. 12, p. 113-124, 2014. Disponível em: https://seer.ufs.br/index.php/revtee/article/view/2959. Acesso em: 3 jan. 2020. DOI: https://doi.org/10.20952/revtee.v0i0.2959.

THÜRLER, D.; DOS SANTOS, J. L. Um debate sobre a escola como tecnologia político-cultural. Revista Tempos e Espaços em Educação, São Cristóvão, v. 7, n. 14, p. 29-44, 2014. Disponível em: https://seer.ufs.br/index.php/revtee/article/view/2950. Acesso em: 3 jan. 2020. DOI: https://doi.org/10.20952/revtee.v0i0.2950.

ULJENS, M. Non-Affirmative curriculum theory in a cosmopolitan era?. Revista Tempos e Espaços em Educação, São Cristóvão, v. 9, n. 18, p. 121-132, 2016. Disponível em: https://seer.ufs.br/index.php/revtee/article/view/4970. Acesso em: 21 jan. 2020. DOI: https://doi.org/10.20952/revtee.v9i18.4970.

VIEIRA, C. M.; COELHO, M. A. Sexualidade e deficiência intelectual: concepções, vivências e o papel da educação. Revista Tempos e Espaços em Educação, São Cristóvão, v. 7, n. 14, p. 201-212, 2014. Disponível em: https://seer.ufs.br/index.php/rev tee/article/view/3268. Acesso em: 3 jan. 2020. DOI: https://doi.org/10.20952/revtee. v0i0.3268. 


\section{Ivanderson Pereira da Silva (Maceió, Alagoas, Brasil) \\ Universidade Federal de Alagoas (UFAL), Departamento de Educação, Curso de Graduação em Pedagogia}

Licenciado em Física (2008), especialista em Mídias na Educação (2010), mestre (2010) e doutor em Educação (2016), todas as formações pela UFAL. É professor da UFAL, campus Arapiraca, atuando nos cursos de licenciatura em Física e Pedagogia. É professor permanente do Programa de Pós-Graduação em Ensino e Formação de Professores da UFAL, campus Arapiraca, e do Programa de Pós-Graduação em Ensino de Ciências e Matemática (CEDU) da UFAL. É líder do Grupo de Pesquisa em Educação, Mídias, Tecnologias e Sociedade (GEEMTS) e atualmente realiza estágio pós-doutoral no Programa de Pós-Graduação em Educação da Universidade Federal de Sergipe.

Contribuição de autoria: Realizou a revisão sistemática do material levantado e contribuiu com a revisão teórico-metodológica.

Lattes: http://lattes.cnpq.br/3106780553307514.

E-mail: ivanderson@gmail.com.

\section{Alfrancio Ferreira Dias (Aracaju, Sergipe, Brasil) \\ Universidade Federal de Sergipe (UFS), Departamento de Educação, Curso de Graduação em Pedagogia}

Pós-Doutor pela University of Warwick (2018), no Reino Unido, e doutor em Sociologia pela UFS. Professor adjunto III do Departamento de Educação da UFS. Coordenador do Programa de PósGraduação em Educação da UFS (Gestão 2016-2018 e Gestão 2018-2020). Vice-Líder do Grupo de Pesquisa: Educação, Formação, Processo de Trabalho e Relações de Gênero, vinculado ao Conselho Nacional de Desenvolvimento Científico e Tecnológico (CNPq). Pesquisador do Núcleo de Estudos e Pesquisas Interdisciplinares sobre a Mulher e Relações Sociais de Gênero (NEPIMG) da UFS. Editor da Revista Tempos e Espaços em Educação desde 2014. Coordenador adjunto do Fórum de Editores de Periódicos da Área de Educação (Fepae/Anped). Editorial Board - Portuguese da Revista Education Review da Arizona State University, Estados Unidos. Visiting Research Fellow no Centre for the Study of Women and Gender da University of Warwick, Reino Unido (2018). Desenvolve pesquisa e extensão nos seguintes temas: Gênero, Sexualidades e Educação; Formação Docente e Diferença; Estudos Curriculares Pós-Críticos; Estudos Queer e Educação; Pedagogias Queer.

Contribuição de autoria: Realizou o levantamento dos artigos e contribuiu com a revisão sistemática e com a revisão teórico-metodológica.

Lattes: http://lattes.cnpq.br/1729817235900990.

E-mail: diasalfrancio@gmail.com.

\section{Pedro Paulo Souza Rios (Salvador, Bahia, Brasil) \\ Universidade do Estado da Bahia (UNEB), Departamento de Educação, Curso de Graduação em Pedagogia}

Doutor em Educação pela Universidade Federal de Sergipe (UFS), mestre em Educação, Cultura e Territórios Semiáridos pela UNEB, especialista em Educação Ambiental pela Facinter, em Filosofia Contemporânea pela Faculdade São Bento e em Educação de Jovens e Adultos pela Universidade Cândido Mendes (UCAM), licenciado em Pedagogia pela UNEB e em Filosofia Faculdade Batista Brasileira (FBB) e Bacharel em Teologia pela Faculdade Católica do Ceará (FCC). Líder do Grupo de Estudos e Pesquisas em Educação, Gênero e Sexualidades do Sertão (Geneses-Sertão). Membro do Grupo de Pesquisa Educação, Sociedade e Desenvolvimento. Atualmente é professor substituto da UNEB, lotado no campus VII, em Senhor do Bonfim. Tem experiência nas áreas de Educação; Gênero e Sexualidade; Metodologia do Trabalho Científico; Filosofia e Filosofia da Educação; Antropologia da Educação e Cultural; Educação de Jovens e Adultos; Educação Contextualizada e Estágio Curricular Supervisionado; e Currículo.

Contribuição de autoria: Realizou a revisão sistemática do material levantado e contribuiu com a revisão teórico-metodológica.

Lattes: http://lattes.cnpq.br/4706453501967580.

E-mail: peudesouza@yahoo.com.br. 
Editora responsável: Lia Machado Fiuza Fialho

Pareceristas ad hoc: Cristine Brandenburg e Karla Angélica Silva do Nascimento

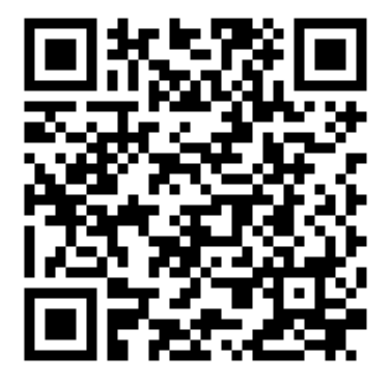

Recebido em 23 de janeiro de 2020.

Aceito em 31 de janeiro de 2020. 